\title{
Extrahepatic Bile Duct Carcinosarcoma
}

National Cancer Institute

\section{Source}

National Cancer Institute. Extrahepatic Bile Duct Carcinosarcoma. NCI Thesaurus. Code C96939.

A carcinoma that arises from the extrahepatic bile ducts and it is characterized by the presence of a sarcomatous component. 